Hospital (Fulham), and to provide a nation-wide service the load will now be shared by laboratories at the Jessop Hospital at Sheffield and in the University of Dundee. It is not, of course, intended that the assay service should replace local follow-up in any way. Clinical examination remains important, particularly in the first few months of follow-up and monthly chest $x$-ray examinations are advisable as long as the gonadotrophin values are abnormal.

As well as providing information to enable the clinician to manage these cases better, the registration scheme should also yield valuable information about various aspects of hydatidiform mole. More information is needed about the risk of choriocarcinoma after subsequent pregnancies and there is a case for further radioimmunoassays at this time. ${ }^{3}$ Dr. Crawford refers to the question of whether there is any risk from the use of oral contraceptives in these patients, and here also registration should provide much needed evidence.

Obviously, the success of a centralized follow-up service will depend on the patients' co-operation. This is more likely to be achieved where the need for follow-up has been carefully explained, and the contribution of the obstetrician to the success of the scheme will be critical. The main results of the scheme should be to ensure that deaths from choriocarcinoma which develops as a complication of hydatidiform mole are eliminated. Another important feature is that the scheme is probably the first large-scale biochemical screening for any form of cancer. Whether screening for cancer in a general sense will ever be possible or desirable is a question for the future, but almost certainly similar screening programmes for other risk groups will follow.

1 Delfs, E., Annals of the New York Academy of Sciences, 1959, 80, 125.
Bagsha

Bagshawe, K. D., Golding, P. R., Orr, A. H., British Medical fournal, $1969,3,733$.

Bagshawe, K. D., Choriocarcinoma. The Clinical Biology of the Trophoblast and its Tumours. London, Arnold, 1969.

4 Bagshawe, K. D., Wilde, C. E., and Orr, A. H., Lancet, 1966, 1, 1118. Wilde, C. E., Orr, A. H., Bagshawe, K. D., Fournal of Endocrinology, $1967,3,23$

6 Midgeley, A. R., Endocrinology, 1966, 79, 10.

\section{Anorexia Nervosa in Males}

Though the syndrome of anorexia nervosa characteristically occurs in young females, ${ }^{1}$ occasional examples of a similar condition affecting males are met with in clinical practice. How the male syndrome should be classified is controversial. Whereas some authors maintain that anorexia nervosa is never found in the male, ${ }^{2-4}$ largely on the grounds that amenorrhoea is an essential criterion for the diagnosis, others claim that anorexia in the male is invariably secondary to other psychiatric disorders. ${ }^{5}$

In a recent paper P. J. V. Beumont, C. J. Beardwood, and G. F. M. Russell ${ }^{6}$ do much to elucidate this problem. They begin by setting out diagnostic criteria for anorexia nervosa. In summary these are behaviour aimed at inducing weight loss, morbid fear of gaining weight, and an endocrine disturbance manifested in females as cessation of menstruation. These authors point out that the rigid application of amenorrhoea as a diagnostic criterion would exclude not only males but also pre-pubertal girls from consideration. They prefer to seek evidence of an analogous endocrine dysfunction in males who display the first two criteria.

Applying these criteria to 250 supposed male cases in the literature Beumont and colleagues are able to accept only 25 as probable cases of anorexia nervosa. To these they add six cases of their own. The clinical picture which emerges is of an onset in late childhood or adolescence, often in someone who is overweight. Refusal of food is often rationalized on the grounds of constipation or abdominal discomfort, and some patients show odd behaviour such as purgation, vomiting, unusually strenuous exercise, and clandestine disposal of food. Obsessional rituals and sexual immaturity or loss of libido are also described. Precipitating factors include fears or conflicts about sexuality, overenthusiastic dieting, and chance remarks about being overweight. The close resemblance to the syndrome in females is obvious. ${ }^{1}$

These authors extended their study into the endocrine field by examining urinary excretion of testosterone in six patients and urinary total gonadotrophic activity in three patients. Both indices gave subnormal results when the patients were emaciated, as in earlier reports, ${ }^{78}$ with a return towards normal levels after proper feeding. These findings parallel those in female patients with anorexia nervosa, in whom urinary total gonadotrophic activity and oestrogen levels are consistently low in the emaciated stage. ${ }^{9}$ However, the endocrine disturbance in females, which affects the rhythmical release of gonadotrophins, appears to be largely independent of the nutritional state. 1 The observations of Beumont and colleagues, though not conclusive, suggest that in males the endocrine abnormality is more directly related to the level of nutrition. Further endocrine studies are needed, but these authors have clearly shown that the clinical picture of anorexia nervosa in the male closely resembles that in the female.

\footnotetext{
1 British Medical fournal, 1971, 4, 183.

Cobb, S., Borderlands of Psychiatry. Cambridge, Mass., Harvard University Press, 1943.

Nemiah, J. C., Medicine, 1950, 29, 225.

4 Kidd, C. B., and Wood, J. F., Postgraduate Medical fournal, 1966, 42, 443. Selvini, P., in Anorexia Nervosa, ed. J. E. Meyer and H. Feldman, p. 96. Stuttgart, Thieme, 1965.

- Beumont, P. J. V., Beardwood, C. J., and Russell, G. F. M., Psychological Medicine, 1972, 2, 216.

7 Bell, E. T., Harkness, R. A., Loraine, J. A., and Russell, G. F. M., Acta Endocrinologica, 1966, 51, 140.

- Ismail, A. A. A., and Harkness, R. A., Acta Endocrinologica, 1967, 56, 469. - Russell, G. F. M., and Beardwood, C. J., in Endocrinology and Human Behaviour, ed. R. P. Michael, p. 310. London, Oxford University Press, 1968.
}

\section{Osteoarthrosis and Fractures of the Upper End of the Femur}

For an elderly person a fractured neck of femur is quite often a death sentence. The patient, usually a woman, moves around her house or flat with gradually diminishing activity as the years pass, managing her affairs with increasing difficulty but coping with them reasonably well. Spending a week away from home with her devoted family, she trips across a rug, cat, or dog, and the accident occurs. Within a few weeks she may have died of cardiac failure, hypostatic pneumonia, thromboembolic disease, or simply as a result of hospitalization, for the elderly do not transplant well or adapt readily to new surroundings.

Osteoporosis increases steadily in the spines of the elderly as they advance in age. It affects women more than men, and it has commonly been noted in patients who suffer fracture 